\title{
Cuando los combes luchaban (1953), de Leoncio Evita Enoy: ¿proceso de perversión o de subver- sión discursiva?*
}

\author{
Nahiyé Léon Camara ${ }^{1}$ \\ Escuela Normal Superior de Abidjan \\ Costa de Marfil (Côte d'Ivoire)
}

\section{Resumen}

En 1953, fecha de publicación de Cuando los combes luchaban, primera novela escrita por un guineoecuatoriano, Leoncio Evita Enoy, Guinea Ecuatorial era una colonia española a la que la metrópoli se negaba a dar la independencia pedida por los guinea$\operatorname{nos}^{2}$. Es la época de "una censura y represión astringentes" (Swanson, 2014: 778) aplicadas por el régimen franquista a su colonia. La ambición de este breve estudio se traduce en las preguntas: ¿cómo alguien puede aceptar despreciarse hasta aprobar los calificativos insultantes que le atribuyen? ¿Por qué proceso discursivo, el autor logra disimular, en la misma obra, críticas tanto

\section{Abstract}

It was in 1953 when was published, Cuando los combes luchaban, first novel written by a man of Equatorial Guinea: Leoncio Evita Enoy. Even though actions of the novel took place in the pre-colonial period, at the time of publication, Equatorial Guinea had still been a Spanish colony which had rejected the independence claimed by the independentists. Through what discursive process does Leoncio Evita Enoy manage to conceal in the samework, criticisms as much towards black culture as to the white one? How does ideology, by which our author seems to legitimize action of invaders, and therefore destruction of a

*Cuando los combes luchaban (1953) by Leoncio Evita Enoy: Process of perversion or discursive subversion?

Recibido: 15 de octubre de 2017 - Aprobado: 10 de enero de 2018

${ }^{1}$ Doctora de tercer ciclo en Estudios Romanes por la Universidad de Montpellier III (Francia). Doctora de la Universidad de Cádiz (España), con mención en Literatura hispano-africana.e-mail: camaeveema@yahoo.fr

2 "La España de Franco, aislada internacionalmente, [...], no estaba muy por la labor de dar la independencia a sus colonias africanas. Bien al contrario, en 1959, las convirtió en provincias españolas de pleno derecho, de tal forma que el estatus de "colonia" desaparecía para ser parte indivisible de España, y así se ahorraba el tener que darles la independencia. El único inconveniente es que no coló" (Castillo, 2014). 
acerca de la cultura negra como de la blanca? En una época en la que el negro no es más que un salvaje según el blanco, ¿cómo Evita Enoy consigue escribir una obra que sea bien acogida por los blancos? En definitiva, reconocida como una obra asimilacionista, no nos queda más que preguntarnos si es pervertida o simplemente subversiva. ¿Incluye rasgos de resistencia frente a la ideología colonialista? Para lograr nuestro propósito, proponemos servirnos de una nueva herramienta, es decir, partir de los condicionantes de producción para analizar la "cantidad de texto" consagrada a los principales temas de la obra.

Palabras clave: disimulación, formación discursiva, novela asimilacionista, novela de resistencia, perversión discursiva. people, manifests itself at the level of discursive formation? Finally, its work recognized as assimilationist, all we have to do is to know whether it is perverted or simply subversive. Does it contain features of resistance to colonialist ideology? To achieve our ambition, we propose to use a new tool, that is to say, be based on the production conditions to analyze "amount of text" devoted to the main themes of the work.

\footnotetext{
"[Leoncio Evita Enoy], todo un mundo, un pueblo, una historia, una etnia, un clan, un hombre. Evita es un talento, un creador, un artista, una pluma, un escritor. Este genio es ante todo y sobre todo el reflejo de una época, el nexo de entronque, el horizonte de una perspectiva"
}

(Mbomio Bacheng, 2000: 72).

\section{Introducción}

Mucho se ha dicho a propósito de Cuando los combes luchaban, primera novela escrita por un guineoecuatoriano, Leoncio Evita Enoy. Los calificativos que le han atribuido son numerosos y muy variados. Considerada por el prologuista Echegaray como "una obrita francamente aceptable diferente de los relatos inconexos y absurdos que algunos 'morenos' seudointelectuales escriben" (González Echegaray, 1995: 11), fue tachada, después, de novela asimilacionista o de consentimiento (Ngom Fayé, 2003: 121). Si 
algunos reconocieron que criticaba tanto las costumbres africanas como las occidentales y aun que incluía marcas de orgullo y resistencia negroafricanas, hay que reconocer que la mayoría de las primeras críticas fueron negativas: "Julián Bibang Oyee, Raquel Llombé, Ciríaco Bokesa, cuando no la ven simplemente como un ejemplo de literatura colonial o de asimilación, la consideran, tal es el caso de Zamora Loboch, como 'un periodismo mal hecho' " (GarcíaAlvite, 2008). La diversidad de opiniones acerca de la obra lleva a Swanson a afirmar que:

\section{[...] a pesar de su reconocimiento como texto fundacional de las letras guineanas, la novela ha provocado cierto malestar, cuando no un debate, tanto entre escritores como críticos guineanos que la han colocado bajo la rúbrica de literatura de consentimiento (Swanson, 2014: 777).}

En la misma idea de la diversidad de opiniones, notamos que, cuando para Onomo-Abena sólo "transpira en filigrana la rebeldía aunque tímida" (Onomo-Abena, 2002: 225), para Marvin Lewis: "aún cuando sea cierto que la novela está escrita desde la perspectiva de un sujeto colonizado, es erróneo asumir que carece de un discurso de resistencia y afirmación de valores africanos" (2007: 111). Pues, de la simple obra asimilacionista, se acabó por reconocer en "la estructura y lenguaje de la novela una resistencia tenaz a la mirada europea, una crítica disimulada, mas no oculta, de la colonización" (Swanson, 2014: 780). Ahora que la mayoría de la crítica es unánime sobre el valor de la obra en la lucha de los guineoecuatorianos por la búsqueda de su dignidad, la cuestión que se plantea es: ¿cómo el autor logra expresar esta resistencia en un contexto en el cual el colonizador mantiene una "censura férrea" (Odartey-Wellington, 2014: 771)? ¿Qué estrategias discursivas emplea para lograr denunciar el estatuto de "salvajes" reservado a los negros en aquella época? Después de los numerosos y muy valiosos estudios realizados ya sobre esta obra ${ }^{3}$, ¿qué más se puede decir de ella? ¿Por qué volver a leerla? ¿Qué pretendemos aportar a su comprensión?

Intentaremos ver, como Swanson (2014) lo hizo, ¿“cómo dentro de la perspectiva local, el conocimiento del espacio y la identidad, anclados en el discurso etnológico, se conjugan hasta llegar a formar un discurso de resistencia que responde a la mirada europea desde el interior del texto mismo"? (777). Nuestra obra se diferencia de

\footnotetext{
${ }^{3}$ Citamos entre otros, Onomo-Abena (2002); Uribe (2004); Swanson (2014); Avome
} Mba (2010); Mbomío Bacheng (2012): Lishey (2006) y Carrasco González (2014). 
cualquier lectura anterior, porque cada una desemboca en una nueva comprensión. Volveremos a leerla pero con otra herramienta. No nos limitaremos sólo a un análisis "intratextual", sino que iremos hasta los condicionantes de producción. Intentaremos comprender cómo, según lo que parece, alguien puede despreciarse hasta aceptar los términos despreciativos que le atribuyen. Esto nos llevará a explorar en toda la obra los términos peyorativos para la raza negra. Una vez apuntados, los situaremos en su contexto de producción para aprehender la filosofía de aquella época, pues el análisis que pretendemos hacer no se centrará en dichas secuencias de manera aislada, sino en función del contexto socio-histórico que condicionó su producción. Siguiendo a Teun Van Djik (1984), afirmamos que:

Tenemos un conjunto de contextos posibles. Uno de los cuales tendrá un status específico, a saber, el del contexto real. El contexto real se define por el período de tiempo y el lugar en que se realizan las tareas comunes del hablante y del oyente (274).

Dicho autor añade:

Una de las tareas [...] es formular las condiciones generales y peculiares que determinan [...] los actos ilocutorios. El segundo conjunto de condiciones se refiere a las estructuras mentales subyacentes de los hablantes y oyentes implicados en la interacción comunicativa, es decir sus necesidades, creencias, conocimientos, intenciones y propósitos (283-284).

Hará falta, pues, diferenciar el contexto real, es decir, la sociedad y el momento en los cuales la obra fue producida, del contexto ficticio, el de la historia anecdótica que cuenta la novela. Poniendo de relieve los condicionantes de los actos locutorios e ilocutorios, comprenderemos mejor el texto.

El autor usará dos técnicas clave en su relato. La primera es la del desplazamiento. En vez de situar la obra en su presente histórico, es decir, en los años 50, se aleja en el tiempo situándola en la época pre-colonial. La segunda es la del enmascaramiento, la disimulación. Finge adoptar el lenguaje y la ideología blancos, pero en realidad, los rechaza introduciendo en la obra unas marcas de resistencia, disimulando sus ideas tras esta doble técnica, hablando como los dominadores quieren que hable, acabando así por pervertir su discurso. Esta relectura de la obra debería permitirnos "reconsiderar el lugar que ocupa en el canon de la literatura guineoecuatoriana 
y examinar sus contribuciones a la comprensión de la cultura y la identidad nacional guineanas" (García-Alvite, 2008) ${ }^{4}$ :

Esta obra marca un hito muy importante e insoslayable en la historia de la literatura hispano-negro-africana. Aunque es "una novela etnológica de las costumbres de la tribu combé en cuyo medio se desarrolla la acción novelesca en el país del Muní, de una época precolonial" (N'gom, 1993).

\section{Contextualización socio-histórica de la novela}

\subsection{Las relaciones entre la colonia Guineana y España}

Los años que transcurren entre el nacimiento de Leoncio Evita, 1929, y el año de publicación de su obra, 1953, corresponden a momentos históricos importantes para Guinea Ecuatorial. La acción transcurre en unos territorios que no están todavía totalmente sometidos por España. La frase del explorador español Martín a su sobrino, frase con la que se concluye la obra: "Vamos hijo, no podemos soñar, no podemos regocijarnos hasta que estas hermosas tierras estén bajo la soberanía de España" (Evita, 1953: 124), nos indica que estamos en el período pre-colonial. La presencia de los misioneros norteamericanos John Stephen y su esposa Miss Leona, junto a la de los españoles y los franceses, refuerza la misma idea. Aunque la novela fue publicada en 1953, es decir, en pleno periodo colonial, alude a la época pre-colonial en la que hubo gran rivalidad entre las diferentes potencias europeas para adueñarse de las tierras africanas consideradas como res nullius, es decir que no pertenecían a nadie.

Como escriben Robert Cornevin y Marianne Cornevin (1964):

Si, avant 1869, il s'agissait d'un duel franco-anglais [...], après 1869 la compétition s'internationalise et prend un caractère très différent du fait de l'apparition des " impérialismes » nationaux : impérialisme français [...], anglais [...], portugais [...], belge, [espagnol]. [...]. La conférence de Berlin réunie de novembre 1884 à

\footnotetext{
${ }^{4}$ Todas las referencias bibliográficas dadas en este trabajo no acompañadas de paginación aluden a documentos electrónicos reseñados en la bibliografía. En cuanto a las paginaciones que aparecen solas sin otra referencia, se refieren a la segunda edición de la obra Cuando los combes luchaban, de Leoncio Evita Enoy, de 1996, realizada en Madrid.
} 
février 1885 a fait admettre les règles diplomatiques qui devaient présider au partage et a été suivie, entre 1885 et 1890 , de la grande ruée vers le centre de l'Afrique (280). ${ }^{5}$

Junto a esto, deberíamos detenernos para recordar las circunstancias socio-políticas de la época de publicación de la obra de Evita Enoy. Thomas Engone (2011) las enmarca claramente en la situación económica de España en los años 50:

[...] Y anotemos que, desde el inicio de la II Guerra Mundial en 1939, el régimen español -proclive a Hitler y Mussolini a pesar de su neutralidad oficial- sufría un aislamiento político y, sobre todo, un embargo económico, [...] hasta ya adentrada la década de los 50, se carecía de todo, e incluso la alimentación estaba racionada. España necesitaba todo tipo de materias primas, y sus colonias africanas podían suministrarle algunas.

Por ello, continúa este autor, quedan patentes las consecuencias que, para Guinea Ecuatorial, tuvo la situación difícil que vivía España:

La primera consecuencia de esa política fue la enajenación de tierras a favor de los colonos, en perjuicio de los nativos. De manera que, a los tradicionales agravios de toda colonización -ausencia de libertad, discriminación racial, sobreexplotación de personas y bienes, desprecio de las culturas autóctonas-, el nacionalismo guineano encontró en las expropiaciones forzosas consagradas por la conocida como "Ley de terrenos", de 4 de mayo de 1948, el argumento básico e inmediato para articular la reivindicación de la soberanía (Ibíd.).

En un contexto histórico en el que España necesita desesperadamente las materias primas de su colonia, se hace "renuente una y otra vez a 'mover ficha' para que Guinea Ecuatorial [llegue] a la independencia de forma pacífica" (Lacosta, 1969). Las reacciones de España frente

\footnotetext{
5 " $\mathrm{Si}$, antes de 1869, se trataba de un duelo franco-inglés [...], después de 1869 la competencia se internacionaliza debido a la aparición de los 'imperialismos' nacionales: imperialismo francés [...], inglés [...], portugués [...], belga [...], [español]. La conferencia de Berlín reunida de noviembre 1884 a febrero de 1885 hizo admitir las reglas diplomáticas que debían presidir al reparto y fue seguida, entre 1885 y 1890, de la gran estampida hacia el centro de África". (La traducción es nuestra).
} 
al deseo independentista de los guineanos fueron inapropiadas ${ }^{6} \mathrm{y}$ totalmente improductivas, porque provocaron más frustraciones y rencores por parte de los negros de la colonia. Una de las primeras decisiones fue la de imponer la censura en la colonia:

En una carta firmada por el presidente de la Junta Censora Colonial, y dirigida al Gobernador General, ése proponía la censura de todo impreso recibido en el servicio de correos destinado a los indígenas. [...] En este caso, no es sólo cuestión de que no podía expresarse libremente en la prensa de las instituciones coloniales, sino que tampoco tenía acceso a las ideas modernas que se manejaban en otros lugares (OdarteyWellington, 773).

La consecuencia de tal censura es que "[...] no se iba a permitir allí la publicación de obras que desde el punto de vista de la Junta Censora y del Gobierno General violaran las normas éticas y morales" (770). Sólo se permite publicar la "clase de historias que desprestigian al africano al mismo tiempo que alaban al europeo" (Ibíd.). En definitiva, en esta situación de censura, con unas condiciones tan restrictivas, ¿cómo pudo Evita Enoy orientar su novela para que fuera no solamente aceptada y publicada por las editoriales españolas, sino, además, leída por un público español? Aun, ¿qué hizo para que la "La novela [fuera] usada por el gobierno de Francisco Franco como muestra de los efectos positivos de la misión civilizadora de España en el África subsahariana" (N'gom, 2002: 13)? Aparentemente, las autoridades españolas se contentaron con un lectura "superficial" de la obra, la cual, concluyeron como los críticos N'gom y Osubita. De éstos últimos, Swanson (2014) dice: "la han colocado bajo la rúbrica de literatura de consentimiento (N'gom, Osubita). La consideran literatura colonial (Bibang Oyee, Ilombé, Bokesa)" (777).

Si en la novela Evita Enoy presenta al negro como una bestia, un animal de bosque, un incapaz, reproduce simplemente la imagen que tienen los blancos de los negros. Pero, entre la realidad efectiva y lo que se decía en público, había una gran diferencia: "El Gobierno español financió proyectos destinados a demostrar lo que ya estaba

\footnotetext{
6 "La primera reacción del gobierno español ante las presiones internas e internacionales fue una estrategia asimilacionista, [...]. Convirtiendo formalmente a los territorios del Golfo de Guinea en dos provincias españolas se pretendía certificar el desmantelamiento del sistema colonial. La asimilación fue de hecho muy imperfecta, pues pervivieron numerosas instituciones y formas coloniales; además, el paso de súbditos a ciudadanos en un régimen como el franquista no significaba en ningún caso un aumento de la participación política" (Campos Serrano, 2003: 177-178).
} 
en el ánimo de todo colonial: la limitada capacidad mental del negro" (Beato-Villarino, 1952: 18). De hecho, en cuatro años se publicaron tres tratados ${ }^{7}$ sobre la inferioridad mental del negro, todos ellos editados por instituciones oficiales. La hipocresía de las autoridades españolas y su doble juego no facilitó el trabajo de creación literaria en la colonia. Gustau Nerín (1998) afirma:

En general, hasta los años cuarenta, las autoridades españolas reconocían la rentabilidad de los territorios guineanos, pero en el discurso oficial se intentaba no poner demasiado énfasis en el trasfondo económico de la colonización, sino bien se destacaban los aspectos religiosos, culturales y morales de ésta. [...] Incluso Franco defendió esta teoría en algunos de sus discursos (21).

En este sentido, Luis Carrascosa (1976) nos da a conocer parte de un discurso del Generalísimo en el que alude a la tarea civilizadora de la colonización española:

Vosotros sabéis que España no es, ni ha sido nunca
colonialista, sino civilizadora y creadora de pueblos, que
es cosa bien distinta. El colonialismo es la explotación
del débil por el fuerte, del ignorante por el avisado; es
la utilización injusta de las energías del país dominado
para beneficiar al país dominante. La labor civilizadora
es, precisamente, todo lo contrario. Es la ayuda del mejor
situado al que lo está menos para hacerle avanzar en la
búsqueda de su propio destino (76).

En este segundo discurso, referido por Cristóbal Fernández (1976), el Caudillo presenta la colonización como una obra meramente caritativa:

Desprovista de prejuicios raciales de ninguna clase, sintiendo profundamente el precepto cristiano de la igualdad de todos los hombres, ni España, ni los españoles se sintieron nunca ajenos, indiferentes o superiores a aquellos pueblos con que vivieron y a los

\footnotetext{
${ }^{7}$ El primero, en 1951, por Ricardo Ibarrola: "Aportación al estudio del nivel mental de los indígenas de Guinea" (Archivos del Instituto de Estudios Africanos, Tomo V, $\mathrm{n}^{\circ} 18$ ). El segundo, en 1952, por Beato Ramón Vicente Villarino: “Capacidad mental del negro" (Madrid: CSIC - IDEA). El tercero, en 1954, por Félix de Valois de Arana: "Estudio psicológico sobre la raza negra" (Conferencia Internacional de Africanistas Occidentales. Dirección General de Marruecos y Colonias, Madrid).
} 
que incorporara a la civilización occidental y cristiana. España, a través de la historia, ha sabido siempre entregarse sin reservas, con amor y con entusiasmo a las necesidades, a los afanes y a las ilusiones de aquellos pueblos a los que fue uniendo sus destinos (48).

Finalmente, ¿compartieron los colonos el discurso oficial o mantuvieron sus prejuicios raciales? Animados por este doble juego de los dirigentes, ¿no tuvieron comportamientos racistas para con los negros? ¿El objetivo de la aventura colonial española fue solamente religioso y civilizador? ¿No hubo ni intención ni intento de sacar provecho económico de la colonia? ¿Fue, en parte, sincero este discurso oficial o totalmente fingido? En definitiva, ¿qué pensaron los colonos de los negros? ¿Cómo se comportaron con ellos?

\subsection{Colonos y Colonizados}

Los colonos no compartieron en nada lo enunciado en los discursos oficiales. Tanto los clérigos como los civiles actuaron como verdaderos amos esclavistas, permitiéndoselo todo: abusos sexuales, malos tratos, trabajos forzados, expoliación. En efecto, Gustau Nerín (1998) lo confirma, citando a Bravo Carbonell (1929):

Pero a pesar de los titánicos esfuerzos argumentales de los teóricos oficialistas, las opiniones de los colonos eran muy claras y opuestas a la retórica caritativa oficial. [...] Según los españoles residentes en Guinea, "es con trabajo como se ha de redimir de la barbarie al salvaje del continente africano” (123).

En cuanto a los clérigos, estaban tan interesados como las autoridades civiles en consolidar la soberanía española sobre la totalidad del territorio guineano (Nerín, 1998: 28). Hablando del trabajo de los religiosos en Guinea, Olo Fernández (2010) escribe:

Durante la etapa colonial la Iglesia sirvió a los intereses coloniales formando parte activa de la maquinaria colonial, como hemos podido ver con su participación en las instituciones locales tales como el Patronato de Indígenas. En palabras de Jacint Creus, los misioneros "impulsaron e impusieron un modelo de colonización basado en un racismo hiperbólico y en una aculturación sin fisuras" 
El estatuto del negro en aquella época puede resumirse en estas palabras de Bravo (1925): "Estudiad a un salvaje del bosque y encontraréis que se parece más al mono que al hombre" (111). Tal concepción se justificará en los años siguientes con muchos escritos de los cuales citaremos sólo dos. Soler (1951), hablando en general de los negros, escribe: "Para muchos españoles, los negros no pasaban de ser una "humanidad de hollín y de cochambre [...], llegando a cuestionarse su esencia humana. Los guineanos eran cuerpos sin alma, bestias cercanas al hombre, sin la facultad de pensar y sentir" (43). En cuanto a Closas (1953), refiere las palabras de un viajero tras su estancia en Guinea:

No he quedado convencido de que el negro era totalmente humano; sus reacciones, su falta de moral, sus apetitos y pasiones, su mentalidad infantil, pero inteligente, su indolencia, su irreductible odio del trabajo, su docilidad ante el palo, los instintos canibalescos, aún entre los más cultos, me han hecho dudar (7).

¿Qué retener de esta contextualización? Las autoridades tienen un doble juego, afirmando oficialmente algo y promoviendo, a escondidas, lo contrario. En la mente de cualquier español, el negro era intelectualmente inferior. Se aproximaba más al animal que al hombre. En pocas palabras, era un salvaje. Pero España necesitaba imperiosamente las riquezas de sus tierras africanas, razón por la que se niega a acordarle la independencia ${ }^{8}$. Para poder seguir manteniendo la propiedad de estos territorios, cualquier veleidad de independencia debe ser reprimida. Estas son, pues, las circunstancias socio-históricas que dificultan a Evita Enoy la publicación su obra.

\section{Los negros hablan: representaciones asumidas y rechazadas}

Como lo escribe Swanson (2014), “[...] interesa ver cómo dentro de la perspectiva local, el conocimiento del espacio y la identidad, anclados en el discurso etnológico, se conjugan hasta llegar a formar

\footnotetext{
8 "Durante los años cincuenta, el incipiente nacionalismo guineano, a través de sus seguidores exiliados en Camerún y Gabón, entró en contacto con la resistencia al colonialismo francés. Para contrarrestar los efectos nacionalistas en Guinea, España utilizó como primera estrategia jurídica la Provincialización de Fernando Póo y Río Muni. Pero esta medida no ofreció a España el resultado apetecido y alimentó las exigencias independentistas [...]. Sin embargo, el Gobierno español no ignoraba que, por mucho que lograra manipular a los nacionalistas blandos, la independencia de Guinea era un proceso ineludible [...]" (Pereira Rodríguez, 2001: 77-78)
} 
un discurso de resistencia que corresponde a la mirada europea desde el interior del texto mismo" (777). Para que su discurso corresponda a la mirada europea, Evita Enoy tiene que fingir adoptar el pensamiento de la época y así emplear el lenguaje de la misma. Si nos parece curioso que un negro desprecie su raza hasta atribuirle los términos muy despreciativos que aparecen en la narración, tenemos que recordar que no hace más que emplear el lenguaje y las imágenes cotidianos de esta época. A continuación, registraremos estos términos e ideas que pueden parecernos "extraños" en boca de un nativo. Para Stanford Berman (1959), para quien la novela es asimilacionista (citado por Odartey-Wellington),

What does the novelist think of his race, his country and colonialism? Evita, in charming Castilian, frankly accepts and humbly adulates European dominance. $\mathrm{He}$ tries to show the ineffectuality of traditional rituals, witch-doctors, and ancestor-worship. He views with abhorrence the pagan practices and fearful uncertainties of "savage" jungle life. [he applauds the Spanish colonial ${ }^{9}$ (Berman, 1959: 272-273).

Como lo dijimos, en el cuadro que sigue vamos a apuntar las expresiones que para los asimilacionistas presentan, a la vez, la verdadera imagen del negro, es decir, la de un ser muy limitado, y la del hombre blanco, casi totalmente positiva. Es obvio que para los "no asimilacionistas", la mayoría de estos términos son desdeñosos y aún insultantes para los negros. Pero mencionaremos también las denuncias sobre la actuación de los blancos y su civilización. Tras hacer este repertorio ${ }^{10}$, calcularemos la "cantidad de texto" consagrada a cada tema. Sin ser un análisis lexicométrico, se apoya, sin embargo, en sus principios, como lo podemos notar en las palabras de Walter Terrazas:

Este enfoque, basado en la aplicación de la estadística a las particularidades de datos textuales, permite analizar e identificar núcleos de significado. (Lebart, Salem, 1994). Es apoyándose en este procesamiento

\footnotetext{
9 "Intenta mostrar la ineficacia de los rituales tradicionales, de los brujos y de la adoración de los ancestros. Ve con horror las prácticas paganas y las incertidumbres espantosas de la vida salvaje en la jungla. [Alaba los méritos del colono español]". (La traducción es nuestra).

${ }^{10}$ Tal repertorio resulta casi siempre subjetivo, pues es discutible. Nunca puede ser exhaustivo. Si para algunos unas expresiones no deben figurar en él, para otros, muchas más expresiones deben formar parte. En definitiva, resulta en gran parte relativo, pues es orientativo.
} 
estadístico [...] que el investigador puede, en un segundo momento, elaborar el significado e interpretar el material textual (2016).

\subsection{Cuadro de repertorio de las secuencias}

\begin{tabular}{|c|l|}
\hline Pág. & Términos del texto \\
\hline 41 & Aquel amanecer fue contemplado por los saltones ojos de un negro \\
\hline 41 & Roku-a-Madiba, el reyezuelo combe \\
\hline 41 & $\begin{array}{l}\text { Había una tercera cama: en ella dormían dos chavales medio } \\
\text { cubiertos por una sucia sábana }\end{array}$ \\
\hline 42 & Tranquilísimo, El salvaje no pareció oir todo el bullicio ratonil \\
\hline 43 & A pesar de que Roku era salvaje, \\
\hline 43 & Despreciaba las creencias del país \\
\hline 43 & $\begin{array}{l}\text { La llegada del equipo evangelista protestante le apartó más del } \\
\text { común sentir de los hombres de su raza. Ya no veneraba a los } \\
\text { curanderos y mucho menos los ensalmos de éstos }\end{array}$ \\
\hline 43 & $\begin{array}{l}\text { Los blancos, decía en varias ocasiones, han sido enviados por Rambé } \\
\text { (Dios) para que nos traigan civilización. Palabras que [...] fueron } \\
\text { mal consideradas por su consejero. Habían traído la más sana } \\
\text { intención de civilizar. }\end{array}$ \\
\hline 48 & $\begin{array}{l}\text { A nosotros tampoco nos conviene vivir junto a ellos; son demasiados } \\
\text { insanos }\end{array}$ \\
\hline 52 & $\begin{array}{l}\text { Si cualquier civilizado presenciara ese acto, [...] lo calificaría como } \\
\text { una barbarie. }\end{array}$ \\
\hline 52 & $\begin{array}{l}\text { En cambio, el corto comprender de aquellos atrasados hombres, } \\
\text { todo eso era precioso }\end{array}$ \\
\hline 54 & $\begin{array}{l}\text { [Upolo (el rey)], dirigiéndose al auditorio: -Hermanos, voy a } \\
\text { aclarar un punto [...]. La civilización que tanto apetecemos es como } \\
\text { una antorcha, alumbra mucho, pero quema todo lo que encuentra a } \\
\text { su paso. iPadres e hijos! Tened cuidado de apartar la luz de vuestros } \\
\text { jóvenes, porque mañana será para ellos su más grande remordimiento. }\end{array}$ \\
\hline 55 & $\begin{array}{l}\text { Demos un vistazo sobre nosotros mismos, portamos grandes pipas, } \\
\text { estamos envueltos en amplios clotes y ahora preferimos el alcohol } \\
\text { de los blancos [...]. Ya estamos viciados }\end{array}$ \\
\hline $\begin{array}{l}\text { Aparecerá el pequeño disco de hierro que ellos dan valor, dominará } \\
\text { vuestras voluntades, habréis de estar sirviendo a hombres cual mujeres. }\end{array}$ \\
$\begin{array}{l}\text { Nuestra educación, que los blancos llaman salvajismo obedece } \\
\text { a nuestra naturaleza. No podemos trocar nuestras costumbres, ni } \\
\text { podemos renunciarlas tampoco. }\end{array}$ \\
\hline
\end{tabular}




\begin{tabular}{|c|c|}
\hline 58 & os indígenas \\
\hline 60 & empezaban la "gran medicina" [del curandero] \\
\hline 63 & $\begin{array}{l}\text { La derrota que acababan de sufrir los guerreros les volvía } \\
\text { melancólicos } \\
\text { No se explicaban cómo el bicho logró esfumarse cuando lo creían } \\
\text { acorralado }\end{array}$ \\
\hline 65 & $\begin{array}{l}\text { El reyezuelo recurrió a todos los artificios para cazar el bicho, pero } \\
\text { resultaron inútiles }\end{array}$ \\
\hline 65 & El negro no supo a que otro recurso atenerse \\
\hline 69 & $\begin{array}{l}\text { [el rey] llevaba un puñal clavado en el omóplato derecho. [...] } \\
\text { Prepara una hamaca, vamos a llevarle a la misión. Puede morir si } \\
\text { descuidamos. }\end{array}$ \\
\hline 71 & $\begin{array}{l}\text { ] está debajo del piso gravemente herido. Va a morir si } \\
\text { curar }\end{array}$ \\
\hline 73 & $\begin{array}{l}\text { La última hazaña del leopardo excitó el favor y el terrorismo. La vida } \\
\text { se volvía imposible. Todo el mundo estaba pendiente de sucumbir el } \\
\text { día menos pensado }\end{array}$ \\
\hline 73 & Upolc \\
\hline 73 & jar aquella miseria \\
\hline 77 & $\begin{array}{l}\text { a marchó de cacería [...] El salvajito pensó que tal vez alguno } \\
\text { amilia se marchaba al otro mundo }\end{array}$ \\
\hline 79 & Fueron llegando gentes de aspecto rudimentario. Iban casi desnudos \\
\hline 80 & $\begin{array}{l}\text { Saboreaban grandes bocanadas de «iboga» (cocaína) mezclada } \\
\text { quizá con vísceras humanas }\end{array}$ \\
\hline 82 & $\begin{array}{l}\text { He de castigar a estos salvajes; ellos tienen la culpa de todas las } \\
\text { desgracias que sufrimos [dijo el hijo del rey] }\end{array}$ \\
\hline 84 & $\begin{array}{l}\text { A muchas jornadas de aquí, hay una choza, albergue de una } \\
\text { secta peligrosa [...] Una tribu extraña, a juzgar por su lenguaje: } \\
\text { antropófagos [dijo el rey] }\end{array}$ \\
\hline $\begin{array}{l}84- \\
85\end{array}$ & $\begin{array}{l}\text { Es mucho mejor organizar una expedición [...] para la cual } \\
\text { necesitaría la ayuda de un blanco. [...] la ayuda de un blanco puede } \\
\text { significar tu victoria, debido ala gran veneración que muchas tribus } \\
\text { nos tienen. [dijo el rey] }\end{array}$ \\
\hline 86 & $\begin{array}{l}\text { Aquellos hombres atrasados poseer una ciencia desconocida por } \\
\text { los pueblos civilizados [dijo el pastor] }\end{array}$ \\
\hline 87 & Había sido secuestrado por una tribu salvaje [dijo el pastor] \\
\hline 87 & Pero hemos perdido una ocasión de conseguir Bolondo. \\
\hline 99 & $\begin{array}{l}\text { Un reyezuelo negro me entregó su bastón para entregárselo a } \\
\text { ustedes }\end{array}$ \\
\hline 99 & Vino a mí el reyezuelo suplicando que le ayudara \\
\hline
\end{tabular}




\begin{tabular}{|c|c|}
\hline 111 & Vas a ser maniatada, dejado bajo la vigilancia de un bárbaro \\
\hline 104 & [en el cayuco de los blancos], cinco indígenas remaban \\
\hline 105 & $\begin{array}{l}\text { Los balengues de allí, no menos salvajes que los pigmeos, al } \\
\text { presentarse la caravana, fueron huyendo uno a uno, hasta que no } \\
\text { se quedó en el poblado ni uno solo }\end{array}$ \\
\hline 106 & El desbosque [...] se hizo a fuerza de látigo \\
\hline 106 & $\begin{array}{l}\text { Mil insectos revoloteaban por el aire. [...] Los mosquitos de } \\
\text { larguísimas patas y tan grandes como un pulgar. Arañas de todas } \\
\text { clases había [...] hasta las gigantescas Y las culebras ifaltaban? Ni } \\
\text { hablar: durante el desbosque se mataron más de diez }\end{array}$ \\
\hline 107 & $\begin{array}{l}\text { ¿Por qué hay tanto ruido? [el negro contestó] El búho está cantando } \\
\text { y tienen miedo. }\end{array}$ \\
\hline 108 & $\begin{array}{l}\text { ¡Éste! -La miss señaló a Vilangua-. Entró cuando dormía. ¡Dios sabe } \\
\text { lo que buscaba! } !^{1}\end{array}$ \\
\hline 110 & $\begin{array}{l}\text { Era negra la noche y el canto de un búho rasgaba de vez en cuando } \\
\text { el cavernoso silencio que reinaba }\end{array}$ \\
\hline 111 & Dejada bajo la vigilancia de un bárbaro \\
\hline 114 & Se marcharon los indígenas \\
\hline 116 & Los dos salvajes prometieron ayudarle \\
\hline 117 & los indígenas se agruparon \\
\hline 117 & El salvaje que hasta entonces permaneció en silencio. \\
\hline 117 & El otro salvaje interpretó \\
\hline 117 & $\begin{array}{l}\text { Varias veces, alguno estaba próximo a pisar una culebra que se deslizaba } \\
\text { silenciosa. Por acá y por allá bramaba alguna feria o rugía algún gorila }\end{array}$ \\
\hline 119 & Aquellos hombres negros [...] ¿eran los demonios? \\
\hline 119 & La desagradable presencia de estos diablos \\
\hline 119 & Esto es una especie de infiernillo preparatorio \\
\hline 120 & ¡Largo de aquí, diablo descornado! \\
\hline 120 & El "demonio" del arpa \\
\hline 121 & Dirigiéndose al salvaje con quien hablaba siempre \\
\hline 122 & $\begin{array}{l}\text { ¿El omnipresente había enviado las fuerzas celestiales para castigar } \\
\text { a Lucifer? }\end{array}$ \\
\hline 123 & $\begin{array}{l}\text { La expedición había llegado a la meta: la secta estaba completamente } \\
\text { descompuesta. }\end{array}$ \\
\hline 123 & Estos son dos los bestias de la secta \\
\hline 123 & Castigar aquellos inocentes, que él creyó los «diablos» de guarda \\
\hline 124 & $\begin{array}{l}\text { Vamos hijo, no podemos soñar, no podemos regocijarnos hasta que } \\
\text { estas hermosas tierras estén bajo la soberanía de España }{ }^{2} \text {. }\end{array}$ \\
\hline
\end{tabular}




\subsection{Análisis del corpus}

Estamos en presencia de 62 unidades que podemos repartir en seis grupos:

El primer grupo está constituido de las palabras y expresiones de desprecio de los negros. Son las secuencias: $1-2-3-4-5-9-10-11-13-17-18$ $-19-20-23-24-25-26-27-28-29-30-32$ $-33-35-36-37-38-39-40-41-42-43-441-$ $45-46-47-48-49-50-52-53-54-55-56-57$ $-58-60 \mathrm{l}-61$. Estamos ante un total de 47 secuencias, o sea, el $75,80 \%$ del corpus.

El segundo pone de relieve la hostilidad de la naturaleza. Lo componen las secuencias: 29 y 51, o sea, el 3,22 \% del corpus.

El tercer grupo presenta la colonización bajo un ángulo positivo. Son las secuencias: $6-7-8-21-22-31-$ 59. Representan el 11,29 \% del corpus.

El cuarto grupo está formado por las expresiones que ponen de realce lo negativo de la civilización europea: 12 y 14 . Son 2 secuencias que constituyen el 3,22 \% del corpus.

El quinto grupo pone de manifiesto lo positivo de la civilización negra. Lo forman 2 secuencias: 15 y 16, lo que es un $3,22 \%$ del corpus.

El sexto grupo denuncia la verdadera intención de los blancos, la de poseer las tierras de la comarca. Son las secuencias 34 y 62, es decir, un 3,22 \% del corpus.

Al reunir los dos primeros grupos, es decir, las secuencias que presentan al "salvaje", con las que muestran la peligrosidad de su medio ambiente, obtendríamos 49 secuencias, casi un $80 \%$ del corpus. ¿Qué lectura se puede hacer de estas cifras? ¿Cuál es su interés?

Este $80 \%$ del corpus representa la imagen del negro, tal como lo quieren ver los blancos: atrasado, feo, sucio, vicioso, supersticioso, antropófago, verdadero demonio e incapaz. A causa de esta misma incapacidad, no pudo descomponer a la secta Bueti durante más de seis meses de combate, lo que logró el hombre blanco en apenas una 
semana. Tal presentación del negro nos lleva a plantearnos: ¿cómo un nativo puede llegar a despreciarse a sí mismo, a sus compatriotas y a la naturaleza de su país? ¿Actúa así por obligación? Porque, al no presentar las cosas de esta forma, ¿no se publicaría su obra? ¿0, quizá, proceda de esta manera porque está convencido del valor de la civilización blanca? Como dice el rey Roku: "Los blancos han sido enviados por Rambé (Dios) para que nos traigan civilización [...] a pesar de su interés por traficar, habían traído la más sana intención de civilizar" (42). Tal posición daría razón a los críticos que consideraron Cuando los combes luchaban como una obra de consentimiento, y aún más, de asimilación.

Parafraseando ${ }^{11}$ a Andrea Ostrov (1997), decimos que:

Hay una oposición paradigmática, la de las [razas]. El pensamiento dicotómico -que organiza el sentido en función de oposiciones duales- encuentra sin duda en la diferencia [racial], -en el dato biológico-, una base material para su propia estructuración. La diferencia [racial] puede ser pensada como oposición fundante de la jerarquía intrínseca de toda relación binaria, en tanto esta diferencia biológica es significativa culturalmente en términos de diferentes valoraciones (301).

En efecto, las parejas negro/blanco; salvaje/civilizado; bestia incapaz/hombre capaz; bosque inhóspito/buenas viviendas, representan la base de la estructuración de la sociedad guineana de la época, tanto en la novela como en la sociedad misma. Pero fingiendo alabar a los blancos en su obra, Evita pone de relieve esencialmente lo negativo del negro. De manera casi imperceptible, con sólo un 3,22 $\%$, se denuncian los peligros de la civilización europea. De la misma manera, es decir, apenas, se atreve a apuntar algo positivo sobre la civilización negra. Hace lo mismo con las verdaderas intenciones de los blancos en sólo dos secuencias, aludiendo a su voluntad de acaparar las tierras guineanas. Esta disimulación y este fingimiento son los que nos llevan a hablar de enmascaramiento o de camuflaje. Se puede admirar la osadía del jefe Roku cuando afirma:

La civilización que tanto apetecemos es como una antorcha, alumbra mucho, pero quema todo lo que encuentra a su paso. ¡Padres e hijos! Tened cuidado de apartar la luz de vuestros jóvenes, porque mañana será para ellos su más grande remordimiento (54).

\footnotetext{
${ }^{11}$ En el texto de Andrea Ostrov, en vez de "racial", se emplea el término "sexual".
} 
De hecho, en esta misma línea, el autor no vacila en hacer decir al mismo Rey: "Nuestra educación, que los blancos llaman salvajismo obedece a nuestra naturaleza. No podemos trocar nuestras costumbres, ni podemos renunciarlas tampoco" (55). En este punto, entendemos mejor la propuesta de Orecchioni (1986). En efecto, para comprender un enunciado, Orecchioni propone que se focalice la atención ya no en el análisis del enunciado mismo, sino en el proceso de gestación de éste, es decir, en el proceso de enunciación, lo que supone tener en cuenta "el conjunto de los condicionantes que se ponen en funcionamiento en el momento de producir un enunciado: quién lo emite, para quién, cuándo, dónde" (Sardella, 2012). En cuanto a Sophie Moiraud (1990), parece dar más detalles sobre lo que Orecchioni llama "proceso de gestación". Enuncia las tres operaciones de la "mise en texte" ("la puesta en texto"). Estas son: la operación de referencia o designación, que consiste en la elección de las palabras y conceptos idóneos; la operación de caracterización o de predicación, que consiste en dar precisiones sobre lo que uno describe, y la operación de enunciación, cada una contando una historia según una serie de códigos que le son personales. Las palabras de Swanson (2014) resumen bastante bien estas operaciones textuales: "El espacio de la novela se convierte en un campo de batalla textual en el que se recrea la lucha por ser de los combes en medio de circunstancias históricas complejas aunque desde una perspectiva guineana" (787).

Los condicionantes del relato de Evita Enoy le han sido dados por el contexto socio-político en el que se produjo la obra. Para la "mise en texte" se ha servido de las circunstancias y del lenguaje de su época. España, que necesita las materias primas de la colonia, se niega a otorgarle su independencia. Además, en el imaginario de la mayoría de los españoles, estas tierras africanas están habitadas por unos salvajes, unas bestias sin alma:

La justificación moral [de tal concepción] -escribe Ferrán Iniesta- era profundamente calvinista: la naturaleza y el salvajismo forma parte del caos mientras que Dios y su criatura humana son creadores de orden, y el orden sólo se obtiene mediante el esfuerzo ya iniciado en el Génesis (Iniesta, 2007: 189).

En definitiva, Leoncio Evita Enoy, en un ejercicio de ecuanimidad, logra escribir una obra bien recibida por el público español, aunque contenga críticas acerca de la civilización europea. Con mucho éxito, consigue unir en la misma obra la imagen que los blancos tienen de los negros, las críticas sobre las dos civilizaciones: la negra y la 
blanca, sin dejar de denunciar el verdadero objetivo de los blancos: el de acaparar las tierras africanas. Para lograr tal unión, Evita Enoy tiene que actuar como verdadero equilibrista. Recordemos que su primera técnica, la del desplazamiento, consiste en no situar la obra en su presente histórico, es decir, en los años 50, sino alejarla en el tiempo, colocando la acción en la época pre-colonial. La segunda, es la del enmascaramiento, de la disimulación. Finge adoptar el lenguaje y la ideología blancos. En realidad, los rechaza introduciendo en la obra unas marcas de resistencia, disimulando sus ideas tras esta doble técnica, hablando como los dominadores quieren que hable y acabando por pervertir su discurso.

La discusión sobre la inclusión o no de la novela en la literatura asimilacionista o de consentimiento parece haber pasado de moda, por estar de acuerdo la mayoría de los críticos con tal conclusión ${ }^{12}$. La verdadera pregunta es: ¿cómo una novela que presenta todas las características de una novela asimilacionista, no lo es en definitiva? El análisis nos permitió ver que el autor, con la técnica del enmascaramiento, logra decir las cosas sin que esto choque al público español. Sin embargo, en nuestra opinión, si con la disimulación pervierte su discurso, porque incluyendo elementos "contradictorios"13 o "engañadores"14, con la misma, logra criticar tanto a los negros como a los blancos, sin ser sancionado.

\section{Conclusión}

A modo de conclusión, intentaremos contestar a la que nos parece ser la pregunta clave: ¿puede ser considerada subversiva o pervertida la obra Cuando los combes luchaban? O por el contrario, ¿su intención es la afirmación identitaria guineoecuatoriana? Si adoptamos la definición de Dufrenne (1977), según la cual "la perversión es una fijación sobre la denegación, que es también una transgresión de la ley" (89), siendo la transgresión "un desafío de lo instituido en función de una posición regresiva" (Lutereau, 2012), nos damos cuenta de que comparte un sema común con el término "subversión". Como afirma García Iturbe: "Cuando se habla de Subversión, estamos

\footnotetext{
12 "La crítica contemporánea descubre en una lectura menos superficial que, más allá del diálogo con la mentalidad colonial, son visibles numerosas muestras de crítica de las costumbres occidentales y africanas, e incluso marcas de orgullo y resistencia negroafricanos" (Ramón Trujillo, 2016).

${ }^{13}$ El mismo Rey Roku, después de afirmar que los blancos han sido enviados por Dios para salvar a los negros, denuncia no sólo la peligrosidad de su civilización a través de la moneda y el alcohol, sino también el verdadero objetivo de los blancos, el de acaparar las tierras africanas.

${ }^{14}$ Finge adoptar el lenguaje y la idea que los blancos tienen de los negros.
} 
hablando de una acción encaminada a fomentar que algo deje de marchar con normalidad, a desviarlo de sus propósitos y objetivos, a promover desorden, perturbación, indisciplina" (García Iturbe, 2009).

Aplicadas estas nociones a Cuando los combes luchaban, podemos decir que Evita Enoy, indignado por la degradante consideración de los colonos para con los negros, adopta una actitud subversiva, pervirtiendo su discurso con la técnica de enmascaramiento o disimulación. En efecto, le hubiera sido imposible quedarse insensible e inerte delante de:

[...]l'évolution du paysage physique, dela recomposition $\mathrm{du}$ paysage ethnique à laquelle prennent part les missionnaires par la transformation en profondeur des identités locales. Ainsi également de la déstructuration et de la prolétarisation progressive des sociétés africaines, que les missions entretiennent tout en continuant de plaider en faveur d'un autre modèle de société (Fauvelle-Aymar, 1999). ${ }^{15}$

El restablecimiento final del "orden y la armonía" por los blancos y la última frase del español Martín ${ }^{16}$ dejan entrever el inicio de un largo periodo de dominación de los pueblos negros por los blancos. Si a primera vista la novela de Evita Enoy revela las costumbres del pueblo combe, al mismo tiempo hace lo mismo con el conflicto identitario que sufren los nativos. Despojados de toda dignidad humana, reducidos al estado de bestias, encuentran a través de su primer novelista, Leoncio Evita Enoy, su portavoz. Este logra denunciar el verdadero problema existencial vivido por los guineoecuatorianos durante el período colonial.

Hablando de las dos primeras novelas guineoecuatorianas - Cuando los combes luchaban (Evita Enoy, 1953) y Una lanza por el boabí (Jones Mathama, 1962)-, Uribe (2004) recoge que "ambas se editaron en España y son ejemplos muy característicos de los que M'baré N'gom ha denominado 'literatura asimilacionista o de consentimiento' "

15 “[...] la evolución del paisaje físico, de la recomposición del paisaje étnico de la cual participan los misioneros para la transformación a fondo de las entidades locales. Así también la progresiva desestructuración y proletarización progresiva de las sociedades africanas, que mantienen las misiones mientras siguen abogando a favor de otro modelo de sociedad". (La traducción es nuestra).

16 "El americano ha ganado lo suyo, ese terreno de Bolondo lo merece por su valor. Vamos hijo, no podemos soñar, no podemos regocijarnos hasta que todas estas hermosas tierras estén bajo la soberanía de España" (124). 
(Uribe, 2004: 93). Llegados a este punto, nos permitimos oponernos a tal lectura de la novela. Enoy no quiere parecer un blanco, sino que quiere que publiquen su obra, obra a través de la cual denuncia el problema identitario que vive su pueblo. Según el propio autor:

Para mí esta obrita representa el éxito de mi deseo de llegar a escribir un libro y legar a las futuras generaciones el testimonio de lo que pude aprender en mi entorno cultural [...] La literatura tradicional es mi fuente de inspiración (Enoy en N'gom, 1996: 33).

Coincidimos, pues, con Gouraige (1977), al afirmar que con este primer novelista guineoecuatoriano,

Un nouveau nègre militant prend naissance [...]. $\mathrm{Au}$ bout de la méditation nègre, il $\mathrm{y}$ a, en plus d'une ambition revendicatrice, l'approfondissement d'un état de frustration fondamentale due au fait que mal situé dans des compartiments dégradants, il ne découvre nulle part ni son ordre, ni sa lumière $(18)^{17}$.

Esta ambición reivindicativa, prueba de su toma de consciencia, se traduce por su discurso y el lenguaje que emplea. Siguiendo siempre a Gouraige, mantenemos que:

L'attitude mentale nègre expliquée en partie par le symbole du masque correspond à l'ambivalence d'une réalité sociale qui oblige le nègre à accueillir à la fois sa négritude, et les données de civilisation qui semblent la nier. Le langage nègre se fait alors révolte et épouse toutes les nuances de l'irritation $(21)^{18}$.

Indignado y enojado por esta situación injusta que vive su pueblo, Evita Enoy se atreve a escribir para denunciar la condición humillante del negro. Como lo afirma Mbomio Bacheng (2000):

\footnotetext{
17 "Un nuevo negro militante nace [...] al final de la meditación negra, hay, además de la ambición reivindicativa, la intensificación de un estado de frustración fundamental debida al hecho de que, mal situado en los compartimentos degradantes, no descubre por ningún sitio ni su orden, ni su luz". (La traducción es nuestra).

18 "La actitud mental del negro explicada en parte por el símbolo de la máscara corresponde a la ambivalencia de una realidad social que obliga al negro a aceptar a la vez su negritud, y los datos de civilización que parecen negarla [...] El lenguaje negro se convierte en rebelión y adopta los matices de la irritación". (La traducción es nuestra).
} 
[La obra de Evita Enoy] es una obra transcendental. Se puede también interpretar la iniciativa de Evita como un acto de resistencia de la cultura africana contra la agresión que representa el sistema colonial. La obra vehicula de ese modo un mensaje preindependentista. Se trata en definitiva de un grito de libertad. Es un discurso etnocentrista marcado por el menosprecio del otro al que se niega la religión, la historia, la escritura y la cultura (72-73).

La lucha de estos pioneros, no sólo en la literatura, sino en la lucha guineoecuatoriana por la libertad, desembocó efectivamente en la independencia declarada el 12 de octubre de 1968. Sin embargo, es una lástima que este menosprecio del otro por el colono haya sido tal vez más acentuado tras la independencia, bajo la dictadura de Francisco Macías Nguema. Es una pena que este grito de libertad no haya sido oído por los nuevos dirigentes. La misma lucha parece seguir hoy en día: "La literatura guineana sale a flote, sus artífices más jóvenes salen a la luz, hablan y gritan también lo mismo: libertad" (Mbomio Bacheng, 2016). Muchos nuevos escritores, de los cuales citaremos sólo a algunos, vienen a enriquecer el escenario literario guineoecuatoriano: Edjanga Jones Ndjoli, Guillermina Mekuy Mba, Melibea Obono, José Siale Djangany, Recaredo Silebo Boturu, Trifonia Melibea Obono. Por su escritura, ahora menos disimulada, menos enmascarada, persiguen el mismo combate iniciado por los ancianos, combate por la libertad y la dignidad del ser guineoecuatoriano.

\section{Bibliografía}

Avome Mba, G. (2010). “Rasgos costumbristas y mágicos en Cuando los Combes luchaban y todas las sangres", Hispanista, vol. XI, № 41 (AbrilMayo): http://www.hispanista.com.br/artigos\%20autores\%20 e\%20pdfs/315.pdf (Consultado el 11 de enero de 2018).

Beato Vicente-Villareño, R. (1952). Capacidad mental del negro. Madrid: CSIC-IDEA.

Berman, S. (1959). "Review: Cuando los combes luchaban: novela de costumbre de la Guinea Española de Leoncio Evita Enoy", Jouranl of Negro History, no 44/3, pp. 272-274.

Bravo Carbonell, J. (1925). En la selva virgen del Muni. Madrid: Imp. Zola Ascasíbar.

. (1929). Territorios españoles del Golfo de Guinea. Madrid: Imp. Zola Ascasíbar.

Campos Serrano, A. (2003). "Nacionalismo anticolonial en Guinea Ecuatorial: de españoles a guineanos", Araucaria. Revista Iberoamericana de Filosofía, Política y Humanidades, vol. 5, no 9, pp. 175-195. 
Carrasco González, A. (2014). "Los primeros novelistas guineanos: Leoncio Evita y Daniel Jones Mathama”, Novela colonial hispanoafricana: http://novela-colonial-hispanoafricana.blogspot.com/2014/04/ [Consultado el 11 de enero de 2018].

Carrascosa, L. (1976). Malabo. Ruptura en Guinea. Madrid: Mayer.

Castillo, I. (2014). "Un despropósito llamado independencia de Guinea Ecuatorial": http://ireneu.blogspot.com/2014/10/undesproposito-llamado-independencia.html [Consultado el 27 de noviembre de 2017].

Closas Miralles, J. (1953). “La Guinea que he visto", Separata de Montaña 23, Centre excursionista de Catalunya, Barcelona.

Cornevin, R. \& Cornevin, M. (1964). Histoire de l'Afrique, des origines à nos jours. Paris: Petite Bibliothèque Payot.

Creus, J. (2010). "Guardianes de la Historia y de la memoria: Tradiciones. Colecciones y otras manifestaciones (In)materiales del período colonial", no 7, Congreso de Estudios Africanos, Lisboa.

Dufrenne, M. (1977). Subversión/Perversión. París: P.U.F.

Engone, T. (2011). “El Gobernador Faustino Ruiz González y el nacionalismo en Guinea Ecuatorial", Guinea-Ecuatorial.net: http://www. guinea-ecuatorial.net/ms/main.asp?cd=ni7849> [Consultado el 11 de septiembre de 2017].

Evita Enoy, L. (1996). Cuando los combes luchaban. Madrid: Agencia Española de Cooperación Internacional.

Fauxelle-Aymar, F. (1999). "Ordre colonial et petits désordres", La rencontre coloniale. Regards sur le quotidien, Paris : Upressa Afrique: https:// www.cairn.info/revue-politique-africaine-1999-2-page-105.htm [Consultado el 10 de diciembre de 2017].

Fernández, C. (1962). Misiones y misioneros en la Guinea Española. Historia documental de sus primeros azarosos días (1883-1912). Madrid: Coculsa.

Fernández, R. (1976). Guinea. Materia Reservada. Madrid: Sedmay.

García-Alvite, D. (2008). "Recuperación de prácticas tradicionales de Guinea Ecuatorial en Cuando los combés luchaban de Leoncio Evita", Espéculo. Revista de estudios literarios, no 39, Universidad Complutense de Madrid.

García Iturbe, N. (2009). "La subversión político ideológica": https://www. alainet.org/es/active/28572> [Consultado el 26 de septiembre de 2017].

González Echegaray, C. (1996). "Prólogo de la 1era Edición de 1953". En Cuando los combes luchaban. Madrid: Agencia Española de Cooperación Internacional, pp. 11-12.

Gouraige, G. (1977). Continuité noire. Dakar Abidjan: Les Nouvelles Éditions Africaines.

Ibarrola, R.(1951). "Aportación al estudio mental de los indígenas de Guinea". Archivos del Instituto de Estudios Africanos. Tomo V, nº 18 . 
Iniesta, F. (2007). Historia del África negra. Barcelona: Ediciones Bellaterra. Jones Mathama, D. (1962). Una lanza por el Boabí. Tip Cat. Casals.

Kerbrat-Orecchioni, Catherine. (1986). La enunciación. De la subjetividad en el lenguaje. Buenos Aires: Hachette.

Lacosta, X. (1969). "España-Guinea, 1969: la estrategia de la tensión” (Parte I de II): http://www.cmeyanchama.com/Documents/Guinee/ Guinee_Espana_1969.pdf [Consultado el 8 de diciembre de 2017].

Lebart, L. \& Salem, A. (1994). Analyse statistique des données textuelles: questions ouvertes et lexicométrie. Paris: Dunod.

Lisley, A. (2006). "No podemos soñar. A Hispanophone African Literary Displacement of the Spanish-American War of 1998", Hispanic journal, vol. XXVII, n¹, pp. 119-134.

Lewis, M. (2007). An Introduction to the Literature of Equatorial Guinea. Columbia: U of Missouri P.

Lutereau, L. (2012). “Perversión, subversión: M. Dufrenne y el psicoanálisis”, ActasdelIColoquiode FenomenologíayPsicoanálisis: http://dspace. uces.edu.ar:8180/xmlui/bitstream/handle/123456789/2827/ Perversion_Lutereau.pdf?sequence=1 [Consultado el 27 de septiembre de 2017].

Mbomio Bacheng, J. (2000). “Leoncio Evita o 'Cuando los combes luchaban': una obra trascendental”, Afro-Hispanic Review, vol. XIX, nํㅜ 1, Guinea Ecuatorial, pp. 72-78.

. (2016). "La Quinta Semana de Literatura Guineoecuatoriana, una fiesta de la selva celebrada en Viena" (escrito con la colaboración de Mischa G. Hendel), Fronterad. Revista digital: http://fronterad. com/?q=14760 [Consultado el 13 de diciembre de 2017].

- (2012). "La originalidad de la literatura guineana", Iberoromania, vol. 73-74, pp. 126-143: https://doi.org/10.1515/ ibero-2011-0005 [Consultado el 9 de enero de 2018].

Moiraud, S. (1990). Une grammaire des textes et des dialogues. Paris: Hachette.

Nerín, G. (1998). Guinea Ecuatorial, historia en blanco y negro (Hombres blancos y mujeres negras en Guinea Ecuatorial, 1943-1968. Barcelona: Ediciones Península.

Ngom, M. (1993). "La literatura africana de expresión castellana: la creación literaria en Guinea Ecuatorial”, Hispania, vol. LXXVI, no 3 (Septiembre), pp. 410-418: http://www.cervantesvirtual.com/ obra-visor/hispania--21/html/p0000001.htm\#I_4_[Consultado el 7 de septiembre de 2017].

- (1996). Diálogos con Guinea. Panorama de la literatura guineoecuatoriana de expresión castellana a través de sus protagonistas. Madrid: Labrys 54 Ediciones.

. (2002). "The Missing Link: African Hispanism at the Dawn of the Millenium", Arachne@Rutgers: Journal of Iberian and Latin American Literary and Cultural Studies 1/1: http://arachne. 
rutgers.edu/vol1_1contents.htm [Consultado el 27 de noviembre de 2017].

. (2003). "Literatura africana de expresión española", Cuadernos del Centro de Estudios Africanos, no 3, pp. 111-135.

Odartey-Wellington, D. (2014). “'Equatorial Guinea is different': literatura colonial de Guinea Española en África Occidental”, Revista Iberoamericana, vol. LXXX, no 248-249 (Julio-Diciembre), pp. 763-776.

Olo Fernández, L. (2010). "Iglesia y Educación en Guinea Ecuatorial: Historia", Centro de Estudios guineoecuatorianos: http://cesge. org/index.php [Consultado el 5 de diciembre de 2017].

Onomo-Abena, S. (2002). "Sujeto cultural colonial y producción literaria en Guinea Ecautorial. Lectura sociocrítica del prólogo de Cuando los combes luchaban (1953) de Leoncio Evita", EPOS, no 18, pp. 215229.

Ostrov, A. (1997) "Género, tela y textos en la escritura de Silvina Ocampo", Le fantastique argentin: Silvina Ocampo; Julio Cortázar. Paris: Presses de la Sorbone Nouvelle, pp. 331.

Pereira Rodríguez, T. (2001). "Descolonización española del Golfo de Guinea (1959-1968)", Misceláneas guineoecuatorianas I Del Estado Colonial al Estado dictatorial. Ciudad: Editorial Tiempos Próximos, pp. 77-86.

Ramón Trujillo, J. (2016). "Edición e introducción". En Cuando los combes luchaban. Madrid: Casa de África: http://casa-de-africa.blogspot. com/2016/06/evita-cuando-los-combes-luchaban.html [Consultado el 10 de diciembre de 2017].

Santibáñez, E. (2013). “Perversión y subversión. ¿Existe la perversión hoy?”, Cultura crítica y periodismo digital: http://revistareplicante. com/perversion-y-subversion/ [Consultado el 3 de septiembre de 2017].

Sardella, S. (2012). "Elementos para el análisis de la subjetividad en el discurso periodístico" http://www.buenastareas.com/ ensayos/Elementos-Para-El-Anc3A1Lisis-De La/78392698.html [Consultado el 7 de septiembre de 2017].

Soler, B. (1951). La selva humillada. Barcelona: Hispano-americana.

Swanson, R. (2014). "Autoetnografía, espacio, identidad y resistencia en la narrativa fundamental de Guinea Ecuatorial: Cuando los combes luchaban (1953) de Leoncio Evita Enoy", Revista Iberoamericana, vol. LXXX, no 248-249, pp. 777-789.

Terrazas, W. (2016). "Análisis lexicométrico aplicado al estudio de las concepciones de aprendizaje", Revista Curitiba, no 61, Brasil, pp. 241-255.

Uribe, A. (2004). "El surgimiento de una literatura hispano-africana: Guinea Ecuatorial”, Boletín Hispánico Helvético, vol. IV, pp. 93-103. 